Rev. Estud. Ling., Belo Horizonte, v. 27, n. 1, p. 299-332, 2019

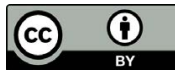

\title{
Jurisprudência sobre a extensão do escopo da Lei Maria da Penha a homens heteroafetivos vítimas de violência doméstica e familiar: análise pragmático-cognitiva
}

\section{Jurisprudence About the Extension of the Scope of Maria da Penha Law to Heterosexual men as Victims of Domestic and Family Violence: Cognitive-Pragmatic Analysis}

Fábio José Rauen

Universidade do Sul de Santa Catarina, Tubarão, Santa Catarina / Brasil fabio.rauen@unisul.br

Bárbara Mendes Rauen

Universidade do Sul de Santa Catarina, Tubarão, Santa Catarina / Brasil barbararauen@gmail.com

Resumo: Analisamos neste artigo jurisprudências sobre a extensão do escopo da Lei Maria da Penha a homens heteroafetivos vítimas de violência doméstica e familiar. Para dar conta desse objetivo, aplicamos o aparato descritivo e explanatório da teoria de conciliação de metas e da teoria da relevância em cinco acórdãos sobre conflitos de competência selecionados dos tribunais de justiça da região sul do Brasil a partir de 2010. Os resultados sugerem haver uma interpretação categórica segundo a qual a Lei Maria da Penha deve ser aplicada somente em casos onde o sujeito passivo de violência doméstica e familiar é mulher (sexo), de modo que os respectivos processos não devem ser julgados por tribunais especiais.

Palavras-chave: pragmática cognitiva; teoria de conciliação de metas; teoria da relevância; Lei Maria da Penha; jurisprudência.

Abstract: We analyze in this article the jurisprudence about the extension of the scope of the Law 11.340/06 - Maria da Penha Law - to encompass heterosexual men as victims of domestic and family violence. We apply the goal-conciliation and relevance-theoretic descriptive and explanatory apparatus on five selected cases of jurisdiction conflicts from the courts of justice of the southern region of Brazil since 2010. The results suggest a 
categorical interpretation according to which the Law should be applied only in cases where the passive subject of domestic and family violence is female (sex), in such a way the cases should not be judged in special courts.

Keywords: cognitive pragmatics; goal-conciliation theory; relevance theory; Maria da Penha law; jurisprudence.

Recebido em 07 de março de 2018

Aceito em $1^{\circ}$ de maio de 2018

\section{Introdução ${ }^{1}$}

A Lei Maria da Penha - Lei n ${ }^{\circ} 11.340$, de 7 de agosto de 2006 - traduz-se em avanço significativo ao proteger mulheres vítimas de violência doméstica e familiar em geral promovida por companheiros e familiares masculinos. Apesar desse mérito inequívoco, persistem aspectos teóricos relevantes sobre sua aplicação, entre os quais o argumento de que fere o princípio da igualdade, uma das cláusulas pétreas da Constituição Federal (BRASIL, 1988), ao proteger somente vítimas femininas. Mesmo que o dispositivo legal possa ser aplicado com certa latitude a transexuais femininas, travestis, drag queens e transformistas (RAUEN, B., 2017), ainda assim pode deixar em desabrigo vítimas heteroafetivas masculinas. Pelicani (2007) segue justamente esse argumento no artigo A Lei Maria da Penha e o princípio da igualdade: interpretação conforme a Constituição, ao propor harmonizar a Lei Maria da Penha com a Constituição, evitando discutir sua possível inconstitucionalidade e, assim, estender sua aplicação a homens vítimas de violência doméstica e familiar.

A extensão do escopo do abrigo da Lei Maria da Penha a vítimas travestis, transexuais e transgêneros do sexo feminino vem sendo acolhida

\footnotetext{
${ }^{1}$ Este artigo foi elaborado como requisito parcial para a conclusão de pesquisa de iniciação científica do Programa Unisul de Iniciação Científica (PUIC). O estudo decorre de pesquisa intitulada Extensão do escopo da Lei Maria da Penha a homens vítimas de violência doméstica e familiar em Pelicani (2007): análise de viés pragmático cognitivo (RAUEN, B., 2015) e está abrigado no Projeto Processos interacionais e conciliação de metas, do Grupo de Pesquisa em Pragmática Cognitiva GPPC (Unisul, IFC, IFSC, Unibave) do Programa de Pós-Graduação em Ciências da Linguagem da Unisul.
} 
pela jurisprudência e encontra fundamento no caput do artigo $5^{\circ}$ da própria Lei em comento, segundo o qual, "para os efeitos desta Lei, configura violência doméstica e familiar contra a mulher qualquer ação ou omissão baseada no gênero que lhe cause morte, lesão, sofrimento físico, sexual ou psicológico e dano moral ou patrimonial: [...]" (grifos nossos). Para Rauen e Rauen (2016), a escolha dos itens lexicais 'mulher' e 'gênero' produz efeitos de sentido. Ao estudarem a interpretação de Dias e Reinheimer (2011) sobre o tema, os autores argumentam que somente "mediante uma interpretação ad hoc do item lexical 'mulher' como gênero, o escopo da Lei" pode ser estendido "a travestis, transexuais e transgêneros do sexo feminino".

A extensão proposta por Pelicani (2007) é ainda mais controversa, pois elege como escopo central da Lei Maria da Penha a violência doméstica e familiar em si mesma e deixa em segundo plano o sexo ou o gênero da vítima. No artigo Extensão do escopo da Lei Maria da Penha a homens vítimas de violência doméstica e familiar em Pelicani (2007): análise pragmático-cognitiva (RAUEN; RAUEN, 2018, inédito), estudamos como o argumento da autora é lógica e epistemologicamente elaborado, ficando por verificar qual é a posição que os colegiados de instâncias superiores assumem em lides nas quais se reivindicam o abrigo da Lei a homens heteroafetivos.

Posto isso, analisamos neste artigo jurisprudências sobre a extensão do escopo da Lei Maria da Penha a homens heteroafetivos vítimas de violência doméstica e familiar com base no aparato descritivo e explanatório da teoria de conciliação de metas de Rauen $(2013,2014)$ e, de modo subjacente, da teoria da relevância de Sperber e Wilson (1995 [1986]). Em outras palavras, pretendemos investigar como os tribunais acolhem esta hipótese de extensão, observando o contínuo argumentativo que procede da instauração do processo até a publicação do acórdão.

Assumindo a teoria de conciliação de metas de Rauen $(2013,2014)$, este estudo se inscreve em proposição recente no domínio da pragmática cognitiva, no qual processos inferenciais abdutivos guiados por metas presumidas sustentam processos interpretativos dedutivos guiados pelas noções cognitiva e comunicativa de relevância. Posto isso, nossa hipótese é a de que a jurisprudência é guiada por uma meta presumida que não somente visa a pacificar o dissenso sobre determinado tema, mas impõe determinada interpretação da Lei sobre outras, a serem silenciadas e interditadas exercendo, simultaneamente, vigilância epistêmica e deôntica (SPERBER 
et al., 2010). Por hipótese, essas condições contextuais devem impor constrições sobre as premissas relevantes mobilizadas abdutivamente na argumentação. Assim sendo, este trabalho testa a pertinência das teorias de conciliação de metas e de relevância conjugadas para descrever e explicar a passagem do texto da Lei para o texto da jurisprudência.

Para dar conta de todas essas demandas, este texto foi organizado em mais quatro seções, dedicadas a observações sobre o escopo da Lei Maria da Penha, à arquitetura descritivo-explanatória, à análise de cinco jurisprudências selecionadas e às considerações finais.

\section{0 escopo da Lei Maria da Penha}

O preâmbulo da Lei Maria da Penha a seguir estampa como objetivo do dispositivo legal a criação de mecanismos para coibição da violência doméstica e familiar contra a mulher. Com a Lei, pretende-se amparar vítimas femininas de violência doméstica, familiar e das relações íntimas de afeto e, assim, diminuir a incidência desse tipo de coação.

Cria mecanismos para coibir a violência doméstica e familiar contra a mulher, nos termos do $\S 80$ do art. 226 da Constituição Federal, da Convenção sobre a Eliminação de Todas as Formas de Discriminação contra as Mulheres e da Convenção Interamericana para Prevenir, Punir e Erradicar a Violência contra a Mulher; dispõe sobre a criação dos Juizados de Violência Doméstica e Familiar contra a Mulher; altera o Código de Processo Penal, o Código Penal e a Lei de Execução Penal; e dá outras providências. (BRASIL, 2006, grifos nossos).

A promulgação da Lei Maria da Penha (BRASIL, 2006) reverbera inúmeras iniciativas em direção à diminuição da violência doméstica e familiar, incluindo tratados e convenções assinadas pelo país no sentido de amparar os direitos das mulheres. Esse é o caso, por exemplo, da I Conferência Mundial sobre a Mulher (1975), que culmina com a Convenção de Eliminação de Todas as Formas de Discriminação contra as Mulheres ou Convenção da Mulher (1984), dispondo sobre os direitos humanos das mulheres, buscando igualdade de gênero e evitando discriminações (PIMENTEL, 1979, p. 2).

Mais recentemente, destaca-se a Convenção Interamericana para Prevenir, Punir e Erradicar a Violência Doméstica ou Convenção de Belém do Pará (1994) que, reconhecendo como fundamentos os 
direitos humanos consagrados pela Declaração Universal dos Direitos Humanos (1948), assume que qualquer violação desses direitos restringe as liberdades fundamentais, desrespeita a Declaração e ofende o princípio da dignidade da pessoa humana (OEA, 1994).

Mesmo diante de todo esse esforço, é apenas em 7 de agosto 2006 que se promulga no Brasil uma Lei específica para combater a violência doméstica e familiar contra mulheres: a Lei 11.340, mais conhecida como Lei Maria da Penha.

Maria da Penha Maia Fernandes sofria agressões de seu excompanheiro. Entre 1997 e 1998, apoiada pelo Centro pela Justiça e Direito Internacional e pelo Comitê Latino-Americano de Defesa dos Direitos da Mulher, formalizou denúncia contra o Brasil na Comissão Interamericana de Direitos Humanos da Organização dos Estados Americanos - OEA (SOUZA, 2009, p. 25), gerando o Relatório 54/01. Diante da inadimplência e por quedar-se inerte perante a acusação, "o Estado brasileiro se viu obrigado a criar uma Lei que desse amparo às mulheres no âmbito da violência intrafamiliar" (RAUEN, B., 2017, p. 24).

Que o escopo da Lei Maria da Penha é o de coibir a violência doméstica e familiar contra a mulher é explícito. Entretanto, a escolha dos itens lexicais 'mulher' e 'gênero' no art. $5^{\circ}$ sugere estender o amparo da Lei a vítimas do gênero feminino como transexuais femininas, travestis, drag queens e transformistas.

Art. $5^{\circ}$ Para os efeitos desta Lei, configura violência doméstica e familiar contra a mulher qualquer ação ou omissão baseada no gênero que lhe cause morte, lesão, sofrimento físico, sexual ou psicológico e dano moral ou patrimonial: [...]. (BRASIL, 2006, grifos nossos).

Rauen, B. (2017) sugere que essa extensão é acolhida nos tribunais. Estudando dois casos de jurisprudência sobre o tema em Tribunais de Justiça Estaduais e quatro decisões em primeira instância, concluiu que os tribunais admitem a aplicação da Lei nesses casos, fazendo prevalecer a noção de gênero sobre a noção de sexo e amparando esse entendimento nos princípios da igualdade e da defesa da dignidade da pessoa humana.

A extensão de escopo para vítimas masculinas, entretanto, encontra resistência mais severa. Para Bianchini (2014, p. 64), a aplicação da Lei 
a homens enquanto sujeitos passivos² é indevida, uma vez que "são as especificidades da violência de gênero (não vislumbradas quando o homem é vítima) que devem servir de fundamento para a incidência da Lei". ${ }^{3}$

Segundo Larrauri (1994 apud BIANCHINI, 2014, p. 64), a violência praticada por mulheres a seus companheiros no âmbito doméstico e familiar possui quatro características em geral: menor intensidade de danos, finalidade de defesa de sua integridade ou da integridade de seus filhos, motivação pontual sem pretensão de castigo ou intimidação do agredido e ausência de produção de temor perdurável.

Pelicani (2007), por sua vez, defende uma extensão radical de escopo, independente de vulnerabilidade, e fundamenta sua argumentação no princípio formal de igualdade estampado no art. $5^{\circ}$ da Constituição Federal, onde se lê que todos devem ser iguais perante a Lei, e reforçado no inciso I, onde se lê que homens e mulheres são iguais em direitos e obrigações.

Art. $5^{\circ}$ Todos são iguais perante a lei, sem distinção de qualquer natureza, $[\ldots]$ :

I - homens e mulheres são iguais em direitos e obrigações, nos termos desta Constituição;

[...]. (BRASIL, 1988, grifos nossos).

Conforme a autora, uma vez que a Lei Maria da Penha elege um gênero como objeto de abrigo legal, ela poderia ser objeto de ação de inconstitucionalidade. Para superar esse impasse, Pelicani (2007) propõe harmonizar a Lei à Constituição pelo princípio da igualdade e, desse modo, estender seu escopo de proteção a vítimas de violência doméstica e familiar, independente de sexo ou gênero do sujeito passivo (cf. RAUEN; RAUEN, 2018. Inédito).

Mesmo o apelo ao princípio da igualdade pode ser rebatido, uma vez que pode ser tratado como mera isonomia formal. Conforme Caixeta (2011, p. 20), uma "[...] igualdade dita formal tem caráter absoluto, podendo gerar inúmeras injustiças, pois esquece que os destinatários da norma têm suas peculiaridades e diferenças". A consideração de peculiaridades e diferenças encontra respaldo na definição aristotélica de

\footnotetext{
${ }^{2}$ Conforme Nucci (2013, p. 187), os titulares protegidos pelo tipo penal incriminador violado.

${ }^{3}$ Se isso pode estar correto para homens heteroafetivos adultos saudáveis, ainda assim valeria questionar a extensão de escopo em casos de vulnerabilidade, quando a vítima masculina é incapaz, menor ou idosa.
} 
igualdade, segundo a qual devemos dar um tratamento igual para os iguais e desigual para os desiguais na medida de suas desigualdades, embora Tavares (2009, p. 570) ressalve que essa definição é antes hipotética, visto que não informa de que maneira ocorre a distinção entre desiguais e iguais. Segundo Araujo e Nunes Júnior (2003, p. 96):

A locução, conquanto correta, parece não concretizar a explicação adequada quanto ao sentido e ao alcance do princípio da isonomia, porque a grande dificuldade reside exatamente em determinar, em cada caso concreto, quem são os iguais, quem são os desiguais e qual a medida dessa desigualdade.

Os autores (2003, p. 97) afirmam que é preciso harmonizar três elementos para aplicar corretamente o princípio da igualdade: o critério discriminador, a correlação lógica entre fator discriminador e tratamento jurídico e a afinidade dessa correlação com valores albergados pela Constituição.

Maia e Bezerra (2017, p. 1703), por sua vez, posicionam-se da seguinte forma quanto à efetividade do princípio da igualdade:

A igualdade efetiva representa a articulação entre a igualdade perante a lei, a redistribuição e o reconhecimento. Nessa perspectiva, revela que a igualdade almejada pela norma não se restringe a um tratamento uniforme a todos, sendo necessário observar as particularidades de cada pessoa individualmente diante das desigualdades do caso concreto, dando passagem às diferenças entre os indivíduos, ou seja, pressupõe tratar diferentemente os desiguais, mas uma diferença que não instigue desigualdades, ao contrário, sob a perspectiva do direito ao reconhecimento. (grifos nossos).

Fundamentadas no princípio da igualdade, Maia e Bezerra (2017, p. 1704) argumentam em favor da extensão de escopo da Lei Maria da Penha às transexuais femininas:

A igualdade como reconhecimento da pessoa transexual significa o respeito a sua identidade e as suas diferenças, de modo a rechaçar as injustiças sociais que lhes atingem, que as fazem detentoras de menor respeito e prestígio social, em virtude de padrões culturais arraigados que as inferiorizam, que as excluem e as rejeitam, perpetuando a dominação cultural, o não reconhecimento ou mesmo o desprezo da pessoa humana transexual. 
Para Bianchini (2014, p. 129), o artigo $5^{\circ}$ caput da Constituição Federal, ao dispor que todos são iguais perante a Lei "sem distinção de qualquer natureza", viabiliza uma interpretação da Lei Maria da Penha fundamentada na noção de gênero. Textualmente:

\begin{abstract}
Os direitos das mulheres são indissociáveis dos direitos humanos: não há que se falar em garantia universal de direitos sem que as mulheres, enquanto humanas e cidadãs, tenham seus direitos específicos respeitados. Tal afirmação é corolário do princípio da igualdade, que determina não poder a Lei fazer qualquer distinção entre indivíduos, o que inclui a distinção entre os sexos ou entre os gêneros.
\end{abstract}

Essa extensão, todavia, não colide com a distinção essencial proposta pela Lei, uma vez que merecem amparo de igual modo mulheres definidas de maneira biológica e social.

Postas essas questões, apresentamos na seção seguinte as ferramentas descritivo-explanatórias de que nos utilizaremos na análise das jurisprudências.

\title{
3 A arquitetura descritivo-explanatória
}

Assumimos neste estudo que a elaboração de uma decisão de segunda instância pode ser modelada ex-post-fato como produto de um plano de ação intencional em direção à consecução ótima de uma meta. Conforme Rauen (2014), um plano de ação intencional pode ser descrito e explicado em quatro estágios: o primeiro estágio consiste em projetar uma meta e é assumido como axiomático; os demais três estágios consistem em formular, executar e checar pelo menos uma hipótese abdutiva antefactual.

Os três primeiros estágios são abdutivos. O estágio [1] equivale a uma descrição do tipo $x$ é $Q$ na qual certo estado $x$ no futuro satisfará uma expectativa de se alcançar certo estado de meta $Q$. O estágio [2] consiste na abdução de pelo menos uma hipótese do tipo $P$ é $Q$, contendo uma ação antecedente $P$ provavelmente suficiente para atingir esse estado de meta $Q$. Segue disso que $x$ é $P$, estágio [3], e o indivíduo $i$ se sente autorizado a executar a ação $P$ na expectativa de atingir $Q .{ }^{4}$

\footnotetext{
${ }^{4}$ Conforme Rauen (2018, p. 17), essa noção de abdução a priori ou antefactual é resultado de uma analogia com abduções explicativas produzidas a posteriori ou pós-
} 
Os três últimos estágios, por sua vez, são dedutivos, na medida em que a hipótese abdutiva antefactual $(P e ́$ é passa a ser tratada pelo indivíduo $i$ como uma premissa maior no estágio [2], a ação antecedente $x$ é $P$ passa a ser tratada como premissa menor no estágio [3], deduzindose daí a conclusão $x$ é $Q$ no estágio [4].

Essa arquitetura pode ser vista na figura a seguir.

FIGURA 1 - Arquitetura abdutivo-dedutiva da teoria de conciliação de metas

\begin{tabular}{|c|c|c|c|c|}
\hline \multirow[t]{2}{*}{ Abdução } & & [1] & & Q \\
\hline & Dedução & [2] & $\mathrm{P}$ & Q \\
\hline & & [3] & $\mathrm{P}$ & \\
\hline & & [4] & & $Q^{\prime}$ \\
\hline
\end{tabular}

Nota: Q' representa a consecução da meta Q.

Fonte: Elaboração dos autores.

Para ilustrar como isso ocorre, vamos analisar a concessão de liminar em agravo de instrumento do Tribunal de Justiça do Mato Grosso do Sul, de 16 de setembro de 2011, citada por Bianchini (2014, p. 65). Nesta liminar, o Des. Dorival Renato Pavan aplica as disposições da Lei Maria da Penha por analogia, deferindo solicitação de proibição de aproximação de esposa agressora, de quem o marido está em processo de separação.

A primeira etapa da análise consiste em arbitrar a meta em questão. Dado que o Des. Dorival Renato Pavan provê agravo de instrumento, assumiremos que sua meta $Q$ é a de julgar procedente agravo de instrumento impetrado por vítima homem de agressora mulher nos termos da Lei Maria da Penha. ${ }^{6}$ Para atingir essa meta $Q$, ele abduz que a decisão deve aplicar a Lei Maria da Penha por analogia inversa $P$.

factuais: "Em abduções explicativas, os indivíduos $i$ observam um evento $Q$ e, ex-postfacto, estabelecem uma hipótese de conexão nomológica entre certa causa antecedente $P$ e esse evento, que é tomado como um estado consequente $Q$ decorrente dessa causa antecedente $P$." Decorre disso que a causa $P$ é a melhor explicação (ou, pelo menos, uma explicação ótima ) para a emergência desse evento consequente $Q$ (PSILLOS, 2002; HARMAN, 1965).

${ }^{5}$ Essa liminar não compõe o corpus de jurisprudências selecionadas neste estudo.

${ }^{6}$ Cabe aqui explicar que a definição de metas e submetas de um plano de ação intencional tem de ser arbitrada conforme o nível de acuidade exigido pela descrição. Sempre é 
Segue disso que ele executa essa ação $P$ em direção ao provimento do agravo de instrumento $Q^{\prime}$.

\begin{tabular}{|c|c|c|}
\hline [1] & & $\begin{array}{l}\text { Q - Julgar procedente agravo de instrumento } \\
\text { impetrado por vítima homem de agressora mulher nos } \\
\text { termos da Lei Maria da Penha, Desembargador. }\end{array}$ \\
\hline [2] & $\begin{array}{l}\text { P-Aplicar a Lei Maria da } \\
\text { Penha por analogia inversa, } \\
\text { Desembargador. }\end{array}$ & $\begin{array}{l}\text { Q - Julgar procedente agravo de instrumento } \\
\text { impetrado por vítima homem de agressora mulher nos } \\
\text { termos da Lei Maria da Penha, Desembargador. }\end{array}$ \\
\hline [3] & $\begin{array}{l}\text { P - O Desembargador aplica } \\
\text { a Lei Maria da Penha por } \\
\text { analogia inversa. }\end{array}$ & \\
\hline [4] & & $\begin{array}{l}\text { Q' - O Desembargador julga procedente agravo } \\
\text { de instrumento impetrado por vítima homem de } \\
\text { agressora mulher nos termos da Lei Maria da Penha. }\end{array}$ \\
\hline
\end{tabular}

Conforme Rauen (2014), dois conceitos emergem no quarto estágio do modelo: o conceito de conciliação de metas e o conceito de confirmação de hipóteses.

Há conciliação de metas $^{7}$ sempre que o estado $Q$ ' do ambiente satisfaz, coincide com ou corresponde com a meta $Q$ e inconciliação de metas nos casos onde isso não ocorre. Visto que a ação antecedente pode ou não ser executada, há (in)conciliações ativas em casos de ação e (in)conciliações passivas em casos de inação. No caso em pauta, dado que a decisão acolhe o agravo de instrumento aplicando a Lei Maria da Penha por analogia inversa, podemos dizer que, do ponto de vista do Desembargador, houve uma conciliação ativa.

Há confirmação de uma hipótese abdutiva antefactual sempre que o estado da realidade $Q$ ' satisfaz, coincide com ou corresponde com a hipótese abdutiva antefactual $H_{a}$, de forma que o resultado da ação $P$ a reforça. ${ }^{8}$ No caso em pauta, houve confirmação de hipótese, pois, do

possível, reconhecemos, não somente considerar submetas cada vez mais detalhadas como também metas de nível mais alto.

${ }^{7} \mathrm{O}$ termo metas está sendo usado em sentido próximo do utilizado em Ciências Contábeis em termos como conciliação bancária ou de balanço.

${ }^{8}$ Conforme o autor, quando a ação $P$ é suficiente, necessária e certa para a consecução $Q$, as hipóteses são categóricas $P \Leftrightarrow Q$; quando a ação $P$ é suficiente, necessária, mas 
ponto de vista do Desembargador, a elaboração do provimento reforça a hipótese que a Lei Maria da Penha pode ser aplicada por analogia inversa a casos de vítimas homens de agressoras mulheres.

O exemplo, até aqui, revisa o que Rauen (2014) chama de autoconciliação, uma vez que o Desembargador, ele mesmo, elabora a hipótese abdutiva antefactual de aplicação da Lei Maria da Penha por analogia inversa e verifica a pertinência dessa hipótese para a conciliação de sua meta. Aspecto diverso é a interpretação dessas consecuções por outras pessoas, que é abrigada pelo conceito de heteroconciliação, especialmente porque a interpretação da Lei Maria da Penha por analogia inversa habilita em caráter liminar a utilização dos dispositivos da Lei Maria da Penha para proteger o marido vítima de agressão, mas não garante seu acolhimento.

Conforme Rauen (2014), toda heteroconciliação de metas demanda por processos comunicacionais sem os quais é impossível às outras pessoas avaliarem a consecução de metas e a confirmação de hipóteses abdutivas antefactuais. Para descrever e explicar esses processos em teoria de conciliação de metas, consideram-se três camadas de intenções, de tal forma que todo estímulo comunicativo corresponde a uma intenção comunicativa superordenada por uma intenção informativa superordenada por pelo menos uma intenção prática.

No caso em pauta, a intenção prática $P$ de aplicar a Lei Maria da Penha por analogia inversa - como subetapa da meta de nível mais alto $Q$ de julgar procedente agravo de instrumento - superordena uma intenção informativa de tornar manifesta ou mais manifesta essa proposição à audiência; e esta intenção informativa superordena a intenção comunicativa de, mediante a formulação do voto, tornar mutuamente manifesto para ambos, desembargador e audiência, que o desembargador comunica essa proposição. ${ }^{9}$

Para a audiência avaliar a proposição do desembargador, é preciso recuperar essas camadas de intenções. Para esse propósito, a teoria de

não é certa para a consecução $Q$, as hipóteses são bicondicionais $P \leftrightarrow Q$; quando a ação $P$ é suficiente, mas não é necessária para a consecução $Q$, as hipóteses são condicionais $P \rightarrow Q$; quando a ação $P$ é necessária, mas não é suficiente para a consecução $Q$, as hipóteses são habilitadoras $P \leftarrow Q$; e, por fim, quando a ação $P$ não é nem suficiente nem necessária para a consecução $Q$, as hipóteses são tautológicas $P-Q$.

${ }^{9}$ Sobre as noções de manifestabilidade e manifestabilidade mútua, ler Sperber e Wilson (1995, p. 38-46). 
conciliação de metas apropria-se do mecanismo de compreensão guiado pela noção teórica de relevância. Em teoria da relevância, define-se por relevância uma função entre efeitos cognitivos positivos maximizados e esforços de processamento minimizados. Os efeitos cognitivos positivos, ou seja, efeitos que contribuem positivamente para o preenchimento de funções ou objetivos cognitivos, são gerados quando processamos um estímulo num contexto de suposições cognitivas prévias. Um estímulo pode fortalecer essas suposições, contradizer e eliminá-las ou ainda gerar implicações - conclusões inferenciais que decorrem da combinação desses estímulos com o contexto cognitivo. Admite-se que, em idênticas as condições, a relevância é maior quando os efeitos cognitivos positivos são maiores e os esforços de processamento necessários para gerar esses efeitos são menores. ${ }^{10}$

A teoria da relevância organiza-se em dois princípios: o princípio cognitivo de que a mente humana maximiza os efeitos cognitivos e o princípio comunicativo de que enunciados, enquanto estímulos ostensivos abertos, são presumidos como otimamente relevantes. Um enunciado é otimamente relevante quando é pelo menos suficientemente relevante para merecer processamento e quando é o estímulo mais relevante que o falante se dispôs a ou foi capaz de produzir. Admitindo-se essa presunção, o intérprete segue uma rota de esforço mínimo com base na decodificação linguística, enriquece o estímulo para obter um significado explícito, sempre que necessário, e completa esse significado em nível implícito, sempre que pertinente.

Procedimento de compreensão guiada pela noção teórica de relevância

Siga um caminho de menor esforço na computação de efeitos cognitivos:

2a. Considere interpretações em ordem de acessibilidade;

2b. Pare quando sua expectativa de relevância é satisfeita.

(WILSON, 2004, lição 5, p. 1).

${ }^{10}$ Sobre as noções de efeitos cognitivos positivos e esforço de processamento, ler especialmente o posfácio da $2^{\mathrm{a}}$ edição de Relevance: communication and cognition (SPERBER, WILSON, 1995). Há uma tradução brasileira deste texto em Sperber e Wilson (2005). 
Como relata Bianchini $(2014$, p. 65$),{ }^{11}$ tendo verificado haver provas suficientes das agressões físicas e psicológicas, o desembargador usou cinco premissas para o acolhimento do agravo de instrumento, dentre as quais destacamos um excerto da primeira premissa. Para dar conta de como se dá a interpretação do excerto conforme o procedimento de compreensão guiado pela relevância, ele foi descrito em quatro versões progressivamente mais complexas. Na versão (1a), representamos a forma linguística do enunciado; na versão (1b), encaixamos a estrutura linguística do enunciado em uma forma lógica; na versão (1c), desenvolvemos a forma lógica a fim de obter sua explicatura; e, na versão (1d), encaixamos a explicatura numa descrição de nível mais alto, que leva em conta a atitude proposicional do falante: ${ }^{12}$

(1a) Forma Linguística: A inexistência de regra específica que preveja medida protetiva de não aproximação destinada ao resguardo dos direitos dos homens (gênero masculino) não é justificativa plausível ao indeferimento de tal pleito, [...].

(1b) Forma Lógica: (ser x (prever x, z), y).

(1c) Explicatura: ${ }^{13} \mathrm{~A}$ inexistência de regra específica $\mathrm{que}$ [REGRA ESPECÍFICA $]_{x}$ preveja medida protetiva de não aproximação

${ }^{11}$ Não obtivemos acesso ao acórdão ou às informações posteriores sobre o processo. Em nota de rodapé, a autora cita o endereço $<\mathrm{http}: / / \mathrm{www} . \mathrm{tjms}$.jus.br/notícias/materia. php?cod=20132> e a data de acesso 2 ago. 2012.

${ }^{12}$ A descrição em quatro etapas sucessivas não deve levar a inferir que a audiência segue essa ordem na interpretação de enunciados, ou seja, primeiro processando a forma linguística para então processar a forma lógica, a explicatura e a atitude proposicional. Assumindo a hipótese de que um conceito cognitivo pode ser acessado por entradas linguísticas, lógicas e lexicais pelo menos, o processamento de um enunciado consiste, em essência, no emparelhamento de entradas linguísticas fornecidas pelo estímulo ostensivo com entradas enciclopédicas da memória, no contexto de uma estrutura ou forma lógica constituída de entradas lógicas. Conforme prevê o procedimento de compreensão guiado pela relevância, esse processo ocorre em ordem de acessibilidade de modo que os estímulos ostensivos linguísticos, na medida em que são processados, fornecem pistas para a atribuição de entradas lógicas, e a formulação lógica fornece hipóteses sobre o emparelhamento de entradas enciclopédicas adequadas e hipóteses antecipatórias sobre a estrutura sintática subsequente e, desse modo, hipóteses antecipatórias sobre entradas linguísticas e enciclopédicas subsequentes.

${ }^{13}$ Conforme Silveira e Feltes (2002, p. 18), apresentamos entre aspas simples as expressões linguísticas quando referenciadas ('Maria'), em versalete minúsculo as entradas enciclopédicas (MARIA) e sem qualquer indicativo as referências no mundo (Maria). 
destinada ao resguardo dos direitos dos homens (gênero masculino) [VÍTIMAS DE AGRESSÃO NO ÂMBITO DOMÉSTICO E FAMILIAR] zão é justificativa plausível ao indeferimento de tal pleito [DE CONCESSÃo DE MEDIDA PROTETIVA DE NÃO APROXIMAÇÃO DESTINADA AO RESGUARDO DOS DIREITOS DOS HOMENS (GÊNERO MASCULINO) VÍTIMAS DE AGRESSÃO NO ÂMBITO DOMÉSTICO E FAMILIAR] $]_{y}$.

(1d) Explicatura expandida: O DESEMBARGADOR DORIVAL RENATO PAVAN AFIRMA QUE A INEXISTENNCIA DE REGRA ESPECÍFICA QUE [REGRA ESPECífICA] PREVEJA MEDIDA PROTETIVA DE NÃO APROXIMAÇÃO DESTINADA AO RESGUARDO DOS DIREITOS DOS HOMENS (GÊNERO MASCULINO) VíTIMAS DE AGRESSÃO NO ÂMBITO DOMÉSTICO E FAMILIAR NÃO É JUSTIFICATIVA PLAUSíVEL AO INDEFERIMENTO DE TAL PLEITO DE CONCESSÃO DE MEDIDA PROTETIVA DE NÃO APROXIMAÇÃO DESTINADA AO RESGUARDO DOS DIREITOS DOS HOMENS (GÊNERO MASCULINO) VÍTIMAS DE AGRESSÃO NO ÂMBITO DOMÉSTICO E FAMILIAR.

Para interpretar a premissa em pauta, assumimos que o intérprete encaixa o enunciado linguístico (1a) numa forma lógica (1b) segundo a qual algo $x$ é algo $y$, tal que esse algo $x$ prevê algo $z$. Na versão (1c), por sua vez, vemos como essa forma lógica vai sendo sucessivamente enriquecida para tornar-se plenamente proposicional e, assim, constituir-se como explicatura do enunciado do juiz. ${ }^{14}$ Para isso, é necessário atribuir o referente REGRA ESPECÍFICA ao pronome relativo 'que' da sentença encaixada; atribuir o referente víTIMAS DE AGRESSÃO NO ÂMBITO DOMÉSTICO E FAMILIAR aos itens lexicais 'homens' e 'gênero masculino', uma vez que a eles se refere a suposta previsão da lei; e atribuir referente CONCESSÃO DE MEDIDA PROTETIVA... ao item lexical 'pleito'. Além disso, o intérprete encaixa essa explicatura numa descrição de nível mais alto (1d) que inclui o ato de fala, algo como $O$ DESEMBARGADOR AFIRMA QUE $\mathrm{P}$, tal que $\mathrm{P}$ equivale à respectiva explicatura.

Admitindo-se a correção da descrição em (1d), perceberemos que sua enunciação só faz sentido se a audiência for capaz de encaixá-la

\footnotetext{
${ }^{14}$ Conforme a teoria da relevância, em geral, os enunciados linguísticos são menos que plenamente proposicionais. Em função disso, eles necessitam ser on-line e pragmaticamente interpretados para constituírem uma proposição completa para a qual é possível atribuir um valor de verdade. Por explicatura de um enunciado, define-se essa proposição completa passível de ser verdadeira ou falsa.
} 
numa cadeia inferencial contendo premissas e conclusões implicadas ${ }^{15}$ cujo resultado é o acolhimento do agravo de instrumento. Algo como:

$\mathrm{S}_{1}{ }^{16}$ - O Desembargador Dorival Renato Pavan afirma que a inexistência de regra específica que preveja medida protetiva de não aproximação destinada ao resguardo dos direitos dos homens (gênero masculino) vítimas de agressão no âmbito doméstico e familiar não é justificativa plausível ao indeferimento do pleito de concessão de medida protetiva de não aproximação destinada ao resguardo dos direitos dos homens (gênero masculino) vítimas de agressão no âmbito doméstico e familiar (premissa implicada derivada da explicatura do enunciado do desembargador). $\mathrm{S}_{2}$ - A Lei Maria da Penha prevê medidas protetivas de não aproximação destinadas ao resguardo dos direitos das mulheres (gênero feminino) vítimas de agressão no âmbito doméstico e familiar (premissa implicada da memória enciclopédica).

$\mathrm{S}_{3}$ - As medidas protetivas de não aproximação destinadas ao resguardo dos direitos das mulheres (gênero feminino) vítimas de agressão no âmbito doméstico e familiar Lei Maria da Penha pode ser aplicada por analogia a homens (gênero masculino) vítimas de agressão no âmbito doméstico e familiar (conclusão implicada por modus ponens conjuntivo: $\left.\mathrm{S}_{1} \wedge \mathrm{S}_{2} \rightarrow \mathrm{S}_{3}\right){ }^{17}$

$\mathrm{S}_{4}$ - As medidas protetivas de não aproximação destinadas ao resguardo dos direitos das mulheres (gênero feminino) vítimas de agressão no âmbito doméstico e familiar Lei Maria da Penha

${ }^{15}$ Sperber e Wilson (1995 [1986]) assumem que os cálculos inferenciais são formados por suposições $\mathrm{S}_{1}-\mathrm{S}_{\mathrm{n}}$ concebidas, conforme o caso, como premissas ou conclusões implicadas.

${ }^{16}$ Por razões de caráter estético, as suposições, embora compostas exclusivamente por entradas enciclopédicas, não estão escritas em versalete ou caixa alta.

${ }^{17} \mathrm{Em}$ teoria da relevância, admite-se que há um módulo interpretativo de caráter dedutivo com livre acesso a suposições da memória ou do ambiente. Este módulo opera, entre outras, por regras como as de eliminação-e e modus ponens. Numa regra de eliminação-e, se consideramos verdadeiras duas suposições $P$ e $Q$ em conjunto, cada uma delas é verdadeira em separado. Em termos próprios da lógica proposicional: " $\mathrm{P} \wedge \mathrm{Q}, \mathrm{P}$ " ou " $\mathrm{P} \wedge \mathrm{Q}$, Q" (tal que $\wedge$ representa a operação lógica de adição). Numa regra de modus ponens, onde há uma relação de implicação entre duas suposições $P$ e $Q$, se a primeira suposição é afirmada $P$, segue-se necessariamente a afirmação da segunda suposição $Q$. Em termos próprios da lógica proposicional: " $\mathrm{P} \rightarrow \mathrm{Q}, \mathrm{P}, \mathrm{Q}$ " (tal que $\rightarrow$ representa a operação lógica de implicação). Por vezes, é possível combinar as duas regras como é o caso do modus ponens conjuntivo: " $(\mathrm{P} \wedge \mathrm{Q}) \rightarrow \mathrm{R}, \mathrm{P} \rightarrow \mathrm{R}, \mathrm{R}$ ” ou então " $(\mathrm{P} \wedge \mathrm{Q}) \rightarrow \mathrm{R}, \mathrm{Q} \rightarrow \mathrm{R}, \mathrm{R}$ ”. 
podem ser aplicadas por analogia à lide (conclusão implicada por modus ponens: $\mathrm{S}_{3} \rightarrow \mathrm{S}_{4}$ ).

\section{Assumindo que a suposição $S_{1}$ representa a intenção comunicativa e que $\mathrm{S}_{4}$ representa a intenção prática em questão, essa cadeia de inferências pode ser descrita em termos de um plano de ação intencional da seguinte forma.}

\begin{tabular}{|c|c|c|c|}
\hline & Intenção Comunicativa & Intenção Informativa & Intenção Prática \\
\hline$[1]$ & & & $\begin{array}{l}\text { P-Aplicar a Lei } \\
\text { Maria da Penha por } \\
\text { analogia inversa, } \\
\text { Desembargador. }\end{array}$ \\
\hline$[2]$ & & $\begin{array}{l}\text { O - Informar que a inexistência de regra } \\
\text { específica que preveja medida protetiva de } \\
\text { não aproximação destinada ao resguardo } \\
\text { dos direitos dos homens (gênero masculino) } \\
\text { vítimas de agressão no âmbito doméstico } \\
\text { e familiar não é justificativa plausível ao } \\
\text { indeferimento do pleito de concessão de } \\
\text { medida protetiva de não aproximação } \\
\text { destinada ao resguardo dos direitos dos } \\
\text { homens (gênero masculino) vítimas de } \\
\text { agressão no âmbito doméstico e familiar, } \\
\text { desembargador. }\end{array}$ & $\begin{array}{l}\text { P-Aplicar a Lei } \\
\text { Maria da Penha por } \\
\text { analogia inversa, } \\
\text { desembargador. }\end{array}$ \\
\hline$[3]$ & $\begin{array}{l}\text { N - Afirmar que a inexistência } \\
\text { de regra específica que } \\
\text { preveja medida protetiva de } \\
\text { não aproximação destinada } \\
\text { ao resguardo dos direitos dos } \\
\text { homens (gênero masculino) } \\
\text { vítimas de agressão no âmbito } \\
\text { doméstico e familiar não } \\
\text { é justificativa plausível ao } \\
\text { indeferimento do pleito de } \\
\text { concessão de medida protetiva } \\
\text { de não aproximação destinada } \\
\text { ao resguardo dos direitos dos } \\
\text { homens (gênero masculino) } \\
\text { vítimas de agressão no } \\
\text { âmbito doméstico e familiar, } \\
\text { desembargador. }\end{array}$ & $\begin{array}{l}\text { O - Informar que a inexistência de regra } \\
\text { específica que preveja medida protetiva } \\
\text { de não aproximação destinada ao } \\
\text { resguardo dos direitos dos homens (gênero } \\
\text { masculino) vítimas de agressão no âmbito } \\
\text { doméstico e familiar não é justificativa } \\
\text { plausível ao indeferimento do pleito de } \\
\text { concessão de medida protetiva de não } \\
\text { aproximação destinada ao resguardo dos } \\
\text { direitos dos homens (gênero masculino) } \\
\text { vítimas de agressão no âmbito doméstico e } \\
\text { familiar, desembargador. }\end{array}$ & \\
\hline
\end{tabular}




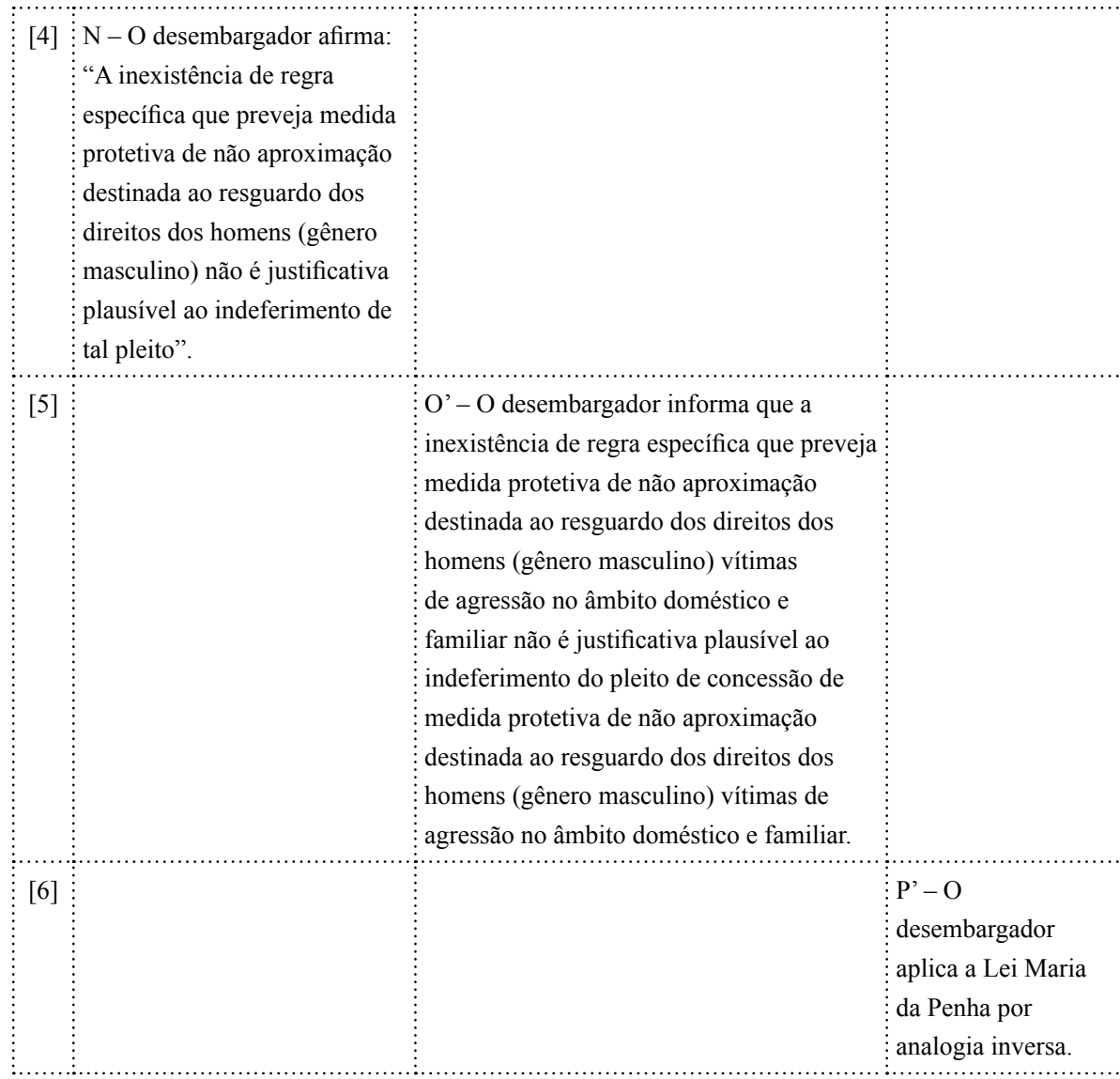

Em síntese, o plano de ação intencional do desembargador consiste de acolher o agravo de instrumento aplicando a Lei Maria da Penha por analogia inversa. Para sustentar essa decisão, ele assume como premissa a inexistência de regra protetiva para o resguardo de vítimas masculinas. Havendo dispositivos na Lei Maria da Penha aplicáveis em circunstâncias similares a mulheres vítimas de agressão doméstica e familiar, em tese, eles podem ser aplicados a homens por analogia. Se isso é verdadeiro em abstrato, é verdadeiro para a lide em questão, razão pela qual resta justificado o pleito. 


\section{Análise das jurisprudências}

Conhecidas, ainda que em linhas gerais, as arquiteturas descritivoexplanatória da teoria de conciliação de metas e da teoria da relevância, estamos em condições de analisar os casos de jurisprudência sobre o tema. Como vimos, o caso destacado por Bianchinni (2014) defere por analogia a aplicação de medidas protetivas previstas na Lei Maria da Penha à vítima masculina de violência doméstica e familiar. Todavia, consulta no acervo de jurisprudências dos Tribunais de Justiça do Rio Grande do Sul, Santa Catarina e Paraná sugere entendimento inverso. Diante da quantidade de acórdãos que caminhavam no mesmo sentido, optamos por selecionar cinco jurisprudências contendo conflitos de competência entre varas especiais que tratam de casos da Lei Maria da Penha e varas que abrangem demais situações do Direito Penal.

Assumindo que as cinco decisões de segunda instância podem ser modeladas pela arquitetura abdutivo-dedutiva de Rauen (2014), todas elas visam a julgar procedente o conflito de competência - a meta prática $Q$ de nível mais alto em questão. O voto dos relatores sugere uma argumentação em dois níveis. Para julgar procedente o conflito, eles argumentam pela inaplicabilidade da Lei Maria da Penha aos casos (submeta $P$ ) e, para concluir que a Lei é inaplicável aos casos, eles destacam que os sujeitos passivos são homens (submeta $O$ ).

\begin{tabular}{|c|c|c|c|}
\hline [1] & & & $\begin{array}{l}\text { Q - Julgar procedente } \\
\text { conflito de competência, } \\
\text { desembargador. }\end{array}$ \\
\hline [2] & & $\begin{array}{l}\text { P-Argumentar que a } \\
\text { Lei Maria da Penha é } \\
\text { inaplicável aos casos, } \\
\text { desembargador. }\end{array}$ & $\begin{array}{l}\text { Q - Julgar procedente } \\
\text { conflito de competência, } \\
\text { desembargador. }\end{array}$ \\
\hline [3] & $\begin{array}{l}\text { O-Destacar o fato de que } \\
\text { o sujeito passivo nos casos } \\
\text { é homem, desembargador }\end{array}$ & $\begin{array}{l}\text { P-Argumentar que a } \\
\text { Lei Maria da Penha é } \\
\text { inaplicável aos casos, } \\
\text { desembargador. }\end{array}$ & \\
\hline
\end{tabular}




\begin{tabular}{|c|c|c|c|}
\hline [4] & $\begin{array}{l}\text { O-O desembargador } \\
\text { destaca o fato de que o } \\
\text { sujeito passivo nos casos é } \\
\text { homem. }\end{array}$ & & \\
\hline [5] & & $\begin{array}{l}\text { P' - O desembargador } \\
\text { argumenta que a Lei Maria } \\
\text { da Penha é inaplicável aos } \\
\text { casos. }\end{array}$ & \\
\hline [6] & & & $\begin{array}{l}\text { Q' - O desembargador } \\
\text { julga procedente conflito } \\
\text { de competência. }\end{array}$ \\
\hline
\end{tabular}

Apresentado em linhas gerais como se organiza o plano de ação intencional nessas decisões, vale identificar como ocorre a argumentação. A rigor, e supostamente porque se trata de uma lide entre heteroafetivos, o que se percebe é um recuo a uma interpretação default ou mais "literal" do item lexical 'mulher' no texto do art. $5^{\circ}$ da Lei, enquanto SER HUMANO DO SEXO FEMININO. Dado que a vítima de agressão não é mulher, resta concluir por negação do consequente ou modus tollendo tollens ${ }^{18}$ que a Lei é inaplicável às lides em questão.

Esse primeiro raciocínio pode ser modelado pelo seguinte argumento condicional:

\begin{tabular}{|c|c|}
\hline $\mathrm{P} \rightarrow \mathrm{Q}$ & Se a Lei Maria da Penha deve ser aplicada, então a vítima deve ser mulher. \\
\hline$\neg \mathrm{Q}$ & A vítima não é mulher (neste caso). \\
\hline$\neg \mathrm{P}$ & A Lei Maria da Penha não deve ser aplicada (neste caso). \\
\hline
\end{tabular}

Uma vez que a Lei Maria não deve ser aplicada a vítimas masculinas, conclui-se que o conflito de competência é procedente. Esse

\footnotetext{
${ }^{18}$ Conforme Rauen (2015, p. 91), "por negação do consequente ou modus tollendo tollens (significando 'modo de negar o negado') define-se um argumento condicional válido que consiste em negar o conteúdo da proposição consequente na segunda premissa. A ideia é que, ao destruir a proposição condicionada ou consequente, destróise a condição antecedente" (itálicos no original).
} 
segundo raciocínio pode ser modelado por afirmação do antecedente ou modus ponendo ponens. ${ }^{19}$

$\neg \mathrm{P} \rightarrow \mathrm{Q} \quad$ Se a Lei Maria da Penha não deve ser aplicada, então o conflito de competência é procedente.

$\neg \mathrm{P} \quad$ : A Lei Maria da Penha não deve ser aplicada (neste caso).

Q O conflito de competência é procedente (neste caso).

Apresentada a linha de argumentação, estamos agora em condições de verificar como esses planos convertem-se em intenções informativas e comunicacionais nos cinco acórdãos selecionados. Nesse propósito, para efeitos de simplificação da exposição, julgamos que o leitor é capaz de inferir que estamos assumindo dois pressupostos em cada uma das análises.

O primeiro deles é o de que, do ponto de vista da teoria de conciliação de metas, os textos dos relatórios consistem em estímulos ostensivos comunicacionais (a intenção comunicativa propriamente dita) com os quais os desembargadores tornam mutuamente manifesto para eles próprios e para a audiência (notadamente, os demais juízes e as partes litigantes) que eles tornaram manifesto certo conjunto de informações $\{\mathrm{I}\}$ (a intenção informativa) que, por sua vez, está a serviço de intenções práticas.

O segundo deles é o de que, do ponto de vista da teoria da relevância, a interpretação dos estímulos comunicacionais pode ser descrita e explicada pelo procedimento de compreensão guiado pela relevância, de tal modo que esses enunciados podem ser encaixados em formas lógicas, a partir dessas formas lógicas podem ser depreendidas as respectivas explicaturas e, a partir dessas explicaturas assumidas como premissas implicadas, podem ser derivadas cadeias de implicaturas.

A primeira jurisprudência ${ }^{20}$ refere-se a inquérito policial sobre suposta ameaça praticada por A. A. G. e V. L. G. contra M. R. V. ${ }^{21}$ Os

\footnotetext{
${ }^{19}$ Confira-se a nota 16.

${ }^{20}$ PARANÁ. Tribunal de Justiça. Conflito de competência crime $n^{\circ}$ 647.834-8. Relator: Des. Luiz Osório Moraes Panza, 25 de fevereiro de 2010. Disponível em: $<$ http://www. tjpr.jus.br>. Acesso em 11 dez. 2017.

${ }^{21}$ Embora públicos, optamos por abreviar os nomes dos litigantes.
} 
autos foram remetidos ao $2^{\circ}$ Juizado Especial Criminal do Foro Central da Comarca da Região Metropolitana de Curitiba, e o Juízo determinou a remessa do feito ao Juizado de Violência Doméstica e Familiar Contra a Mulher. O conflito de competência, que obtém parecer favorável da Procuradoria Geral de Justiça, decorre do fato de a vítima ser do sexo masculino.

O Des. Luiz Osório Moraes Panza inicia seu relatório retomando a ementa da Lei Maria da Penha. Em seguida, destaca os sujeitos ativos e passivos a que a Lei se refere.

Esta lei aplica-se sempre quando se tratar de violência cometida no âmbito das relações domésticas e familiares, [...], independentemente do gênero do sujeito ativo.

Contudo, no que tange ao sujeito passivo, a questão é resolvida de forma bastante simples ao verificarmos que a Lei Maria da Penha, em toda a sua redação, refere-se apenas à mulher como vítima. (grifos nossos).

Como se pode observar, ao definir "de forma bastante simples" que o sujeito passivo tem de ser mulher, o desembargador conclui que a lei é inaplicável ao caso.

$\mathrm{S}_{1}$ - A Lei Maria da Penha refere-se [Lei Maria da Penha] apenas à mulher como vítima de violência cometida no âmbito das relações domésticas e familiares em toda a sua [da Lei Maria da Penha] redação (premissa implicada derivada da explicatura do enunciado do desembargador).

$\mathrm{S}_{2}-\mathrm{A}$ vítima M. R. V. é homem no conflito de competência ${ }^{22}$ (premissa implicada proveniente da memória enciclopédica ou dos estímulos ostensivos dos autos).

$\mathrm{S}_{3}$ - As medidas protetivas de urgência da Lei Maria da Penha não devem ser aplicadas no conflito de competência porque a vítima M. R. V. é homem (conclusão implicada por modus ponens conjuntivo: $\mathrm{S}_{1} \wedge \mathrm{S}_{2} \rightarrow \mathrm{S}_{3}$ ).

\footnotetext{
${ }^{22}$ A rigor: "no conflito de competência entre o $2^{\circ}$ Juizado Especial Criminal do Foro Central da Comarca da Região Metropolitana de Curitiba e o Juizado de Violência Doméstica e Familiar Contra a Mulher". Neste e nos demais casos de remissão às lides, optamos por simplificar a exposição.
} 
Segundo o desembargador, "como o próprio nome diz", compete ao Juizado Especial de Violência Doméstica e Familiar Contra a Mulher processar e julgar os "crimes decorrentes da prática de violência doméstica e familiar contra a mulher e respectivas medidas protetivas de urgência". Sendo assim, decide-se que a "a competência para processar e julgar o presente caso se firme no $2^{\text {a }}$ Juizado Especial Criminal do Foro Central da Comarca da Região Metropolitana de Curitiba", razão pela qual e com máxima urgência, devem-se "adotar as providências necessárias no sentido de agilizar a marcha processual".

A respectiva cadeia de inferências pode ser assim modelada.

$\mathrm{S}_{1}$-As medidas protetivas de urgência da Lei Maria da Penha não devem ser aplicadas no conflito de competência porque a vítima M. R. V. é homem (premissa implicada).

$\mathrm{S}_{2}-\mathrm{O}$ Juizado Especial de Violência Doméstica e Familiar Contra a Mulher não é competente para julgar o caso de M. R. V. (conclusão implicada por modus ponens: $\mathrm{S}_{1} \rightarrow \mathrm{S}_{2}$ ).

$\mathrm{S}_{3}-\mathrm{O}$ conflito de competência procede (conclusão implicada por modus ponens: $\mathrm{S}_{2} \rightarrow \mathrm{S}_{3}$ ).

$\mathrm{S}_{4}$ - A competência para processar e julgar o presente caso deve firmar-se no $2^{\mathrm{a}}$ Juizado Especial Criminal do Foro Central da Comarca da Região Metropolitana de Curitiba (conclusão implicada por modus ponens: $\mathrm{S}_{3} \rightarrow \mathrm{S}_{4}$ ).

$\mathrm{S}_{5}-\mathrm{O} 2^{\circ}$ Juizado Especial Criminal do Foro Central da Comarca da Região Metropolitana de Curitiba deve adotar as providências necessárias no sentido de agilizar a marcha processual (conclusão implicada por modus ponens: $\mathrm{S}_{4} \rightarrow \mathrm{S}_{5}$ ).

A segunda jurisprudência refere-se a conflito negativo de competência suscitado pelo Dr. Juiz de Direito da $3^{\text {a }}$ Vara Criminal da Comarca de Pelotas face a redistribuição do feito determinada pelo Dr. Juiz de Direito do JECRIM ${ }^{23}$ da mesma Comarca, ao entender que a competência para julgamento é do Dr. Juiz de Direito do JECRIM. ${ }^{24}$ Segundo o suscitante, o feito trata, em tese, de crimes tipificados nos

\footnotetext{
${ }^{23}$ Por JECRIM, sigla de Juizado Especial Criminal, define-se um órgão da Justiça Ordinária com competência para julgar crimes considerados de menor potencial ofensivo. ${ }^{24}$ RIO GRANDE DO SUL. Tribunal de Justiça. Conflito de Jurisdição no 70044908549. Relator: Des. Marco Aurélio de Oliveira Canosa, 10 de maio de 2012. Disponível em: $<$ http://www.tjrs.jus.br>. Acesso em 11 dez. 2017.
} 
artigos 147 e 163 do Código Penal. Uma vez que o sujeito ativo neste processo é M. S. C., de 26 anos, e o sujeito passivo é seu pai N. P. C., de 60 anos, argumenta que a Lei Maria da Penha não se aplica ao caso. A Procuradoria de Justiça opinou pela procedência do conflito.

O Des. Marco Aurélio de Oliveira Canosa começa seu voto, tornando mutuamente manifesto o Boletim de Ocorrência 6047/2010 da Delegacia de Polícia Civil de Pelotas, que originou o procedimento. Segundo Canosa, "Resulta, daí, que há noticia criminis relativa à prática dos delitos de dano e ameaca, sendo apontado como autor M. S. C. (filho da vítima), constando como vítima seu pai, N. P. C." (grifos no original, abreviaturas nossas). Em seguida, o desembargador profere sua conclusão: "Constando como vítima um homem - no caso, o pai do acusado -, não há incidência da Lei 11.340/06".

Para fundamentar sua decisão, Canosa opta por tornar mutuamente manifesto três casos precedentes da Corte.

"CONFLITO DE COMPETÊNCIA. LEI MARIA DA PENHA. VÍTIMA. HOMEM. A lei Maria da Penha foi criada para dar proteção à mulher. Quando a vítima do crime for um homem, não se aplica a Lei Maria da Penha.. CONFLITO DE COMPETÊNCIA PROCEDENTE."

(Conflito de Jurisdição No 70042334987, Terceira Câmara Criminal, Tribunal de Justiça do RS, Relator: Nereu José Giacomolli, Julgado em 19/05/2011) - destaquei

"CONFLITO NEGATIVO DE COMPETÊNCIA. LEI MARIA DA PENHA. CRIME DE MAUS TRATOS PRATICADO PELA MÃE CONTRA O CASAL DE FILHOS. NÃO INCIDÊNCIA DA LEI 11.340/06. Havendo estatuto próprio de proteção da criança vítima de violência, não se pode aplicar indistintamente uma lei criada com a finalidade de proteger a mulher da violência masculina, em razão, principalmente, da sua inferioridade física. Aliado a isso, a aplicação da Lei Maria da Penha só ocorre quanto aos fatos praticados por homem contra mulher, 0 que inocorre in casu, devendo o feito ser apreciado pelo juízo comum suscitado. CONFLITO NEGATIVO JULGADO PROCEDENTE. COMPETÊNCIA DO JUÍZO SUSCITADO.” (Conflito de Jurisdição $\mathbf{N}^{\circ} \mathbf{7 0 0 4 6 6 8 2 4 9 8}$, Terceira Câmara Criminal, Tribunal de Justiça do RS, Relator: Francesco Conti, Julgado em 09/02/2012) - destaquei 
"CONFLITO DE COMPETÊNCIA. VIOLÊNCIA DOMÉSTICA. LEI N ${ }^{\circ} 11.340 / 06$. DESCABIMENTO. JUIZADO ESPECIAL CRIMINAL COMPETENTE PARA INSTRUIR E JULGAR O FEITO. AUSENCIA DE FATOS QUE ENSEJEM A INCIDÊNCIA DAS MEDIDAS PREVISTAS NA LEI MARIA DA PENHA. VIOLÊNCIA DE HOMEM CONTRA HOMEM. RÉU DENUNCIADO POR INFRAÇÃO AO ART. 129, CAPUT, DO CÓDIGO PENAL, AINDA QUE, EM TESE, O FATO DEVESSE SER ENQUADRADO NO $\S 9^{\circ}$ DAQUELE DISPOSITIVO. Conflito de jurisdição julgado improcedente." (Conflito de Jurisdição No $\mathbf{7 0 0 4 0 0 5 5 9 7 2 , ~ P r i m e i r a ~ C a ̂ m a r a ~}$ Criminal, Tribunal de Justiça do RS, Relator: Manuel José Martinez Lucas, Julgado em 16/03/2011) - destaquei. (grifos no original).

Em comum, os três casos precedentes da corte referem-se à inaplicabilidade da Lei quando o sujeito passivo é homem, seja adulto, seja criança, independentemente de o sujeito ativo ser mulher ou homem. Segue disso o voto no sentido de "julgar procedente o conflito, para fixar como competente para exame da matéria o Juiz de Direito do JECRIM da Comarca de Pelotas".

Posto isso, o argumento pode ser assim modelado.

$\mathrm{S}_{1}$ - A Lei Maria da Penha não deve ser aplicada em casos nos quais a vítima é homem (premissa implicada).

$\mathrm{S}_{2}$ - Três precedentes da Corte consideram inaplicável a Lei Maria da Penha em casos de vítimas masculinas (premissa implicada). $\mathrm{S}_{3}$-A vítima é homem no conflito de jurisprudência entre $3^{\mathrm{a}}$ Vara Criminal da Comarca de Pelotas e o JECRIM da Comarca de Pelotas (premissa implicada).

$\mathrm{S}_{4}-\mathrm{O}$ conflito de jurisprudência entre a $3^{\mathrm{a}}$ Vara Criminal da Comarca de Pelotas e o JECRIM da Comarca de Pelotas é procedente (conclusão implicada por modus ponens conjuntivo: $\left.\mathrm{S}_{1} \wedge \mathrm{S}_{2} \wedge \mathrm{S}_{3} \rightarrow \mathrm{S}_{4}\right)$.

$\mathrm{S}_{5}-\mathrm{O}$ Juiz de Direito do JECRIM da Comarca de Pelotas é competente para julgar o caso (conclusão implicada por modus ponens: $\mathrm{S}_{4} \rightarrow \mathrm{S}_{5}$ ).

A terceira jurisprudência trata de conflito de competência, com parecer favorável da Procuradoria de Justiça, suscitado pelo Juiz da $2^{\text {a }}$ Vara Criminal de Caxias do Sul, contra decisão do magistrado do Juizado 
Especial Criminal, que "determinou a redistribuição do feito àquele Juízo, por entender tratar o caso dos autos de matéria relativa à violência doméstica e familiar contra a mulher". ${ }^{25} \mathrm{O}$ caso refere-se à prática do delito de ameaça de A. F. S. contra J. M. O., seu ex-companheiro.

O Des. Luiz Mello Guimarães relata que o conflito de competência deve prosperar, uma vez que considera "não ser aplicável na hipótese dos autos a Lei $\mathrm{n}^{\mathrm{o}} 11.340 / 2006,{ }^{26}$ pois a vítima, no caso, é do sexo masculino" (grifo nosso).

Nesse excerto, o argumento subjacente pode ser assim modelado:

$\mathrm{S}_{1}-\mathrm{A}$ vítima J. M. O. no caso de conflito de competência suscitado pelo Juiz da $2^{\mathrm{a}}$ Vara Criminal de Caxias do Sul contra decisão do magistrado do Juizado Especial Criminal é do sexo masculino (premissa implicada com base na explicatura dos enunciados do desembargador).

$\mathrm{S}_{2}-\mathrm{A}$ Lei no $^{\circ}$ 11.340/2006 [Lei Maria da Penha] não é aplicável na hipótese dos autos conflito de competência (conclusão implicada por modus ponens $\mathrm{S}_{1} \rightarrow \mathrm{S}_{2}$ ).

$\mathrm{S}_{3}-\mathrm{O}$ conflito de competência deve prosperar (conclusão implicada por modus ponens $\mathrm{S}_{2} \rightarrow \mathrm{S}_{3}$ ).

A constatação de que a vítima é homem sustentará, em seguida, o encaminhamento do processo para o Juizado Especial Criminal de Caxias do Sul.

Ora, o juizado de Violência Doméstica e Familiar contra a Mulher não é competente para o julgamento de crime de ameaça, mesmo que no âmbito doméstico, contra a vítima homem.

[...].

Ante o exposto, JULGO PROCEDENTE o conflito de competência para declarar competente o juízo do Juizado Especial Criminal da Comarca de Caxias do Sul.

Esse argumento pode ser assim modelado:

\footnotetext{
${ }^{25}$ RIO GRANDE DO SUL. Tribunal de Justiça. Conflito de jurisdição $n^{\circ} 70062842471$ $\left(n^{\circ}\right.$ CNJ: 0476810-53.2014.8.21.7000). Relator: Des. Luiz Mello Guimarães, 12 de fevereiro de 2015. Disponível em: <http://www.tjrs.jus.br>. Acesso em 11 dez. 2017. ${ }^{26}$ Mais adiante, o desembargador afirma que "Assim, em sendo vítima um homem - no caso, o ex-companheiro da acusada -, não há incidência da Lei 11.340/06", citando o artigo $5^{\circ}$ da Lei 11.340/06 como fundamento.
} 
$\mathrm{S}_{1}$ - A vítima J. M. O. no caso de conflito de competência é do sexo masculino (premissa implicada com base na explicatura dos enunciados do desembargador).

$\mathrm{S}_{2}$ - O juizado de Violência Doméstica e Familiar contra a Mulher não é competente para o julgamento de crime de ameaça contra a vítima homem mesmo que no âmbito doméstico (premissa implicada com base na explicatura dos enunciados do desembargador).

$\mathrm{S}_{3}$ - Guimarães julga procedente o conflito de competência de competência para declarar competente o juízo do Juizado Especial Criminal da Comarca de Caxias do Sul (conclusão implicada por modus ponens conjuntivo: $\mathrm{S}_{1} \wedge \mathrm{S}_{2} \rightarrow \mathrm{S}_{3}$ ).

O quarto caso refere-se a "recurso de apelação interposto em face do indeferimento de medidas protetivas pleiteadas em favor de D. S. G." (abreviatura nossa) ${ }^{27}$. O apelante argumenta ser vítima de violência doméstica e que a Lei Maria da Penha pode ser aplicada por analogia por tratar-se de idoso vulnerável.

O Des. Jayme Weingartner Neto assim se posiciona:

A fixação de competência no âmbito dos Juizados de Violência Doméstica e Familiar, criados pela Lei 11.340/06, depende da análise de três vetores que indicam, quando presentes de forma cumulativa, a incidência da cognominada Lei Maria da Penha.

A um, a existência de relação íntima de afeto entre agressor e vítima; a dois, a violência de gênero, direcionada à prática delitiva contra mulher; e, a três, a situação de vulnerabilidade da vítima em relação ao agressor.

No caso dos autos, tratando-se de vítima do sexo masculino, inviável reconhecer a incidência da Lei $\mathrm{n}^{\circ}$ 11.340/06 que visa coibir a violência de gênero. Portanto, em se tratando de lei que visa à proteção especial às mulheres, inviável acolher o presente pleito. (negritos no original).

${ }^{27}$ RIO GRANDE DO SUL. Tribunal de Justiça. Apelação crime $n^{\circ} 70063020689\left(n^{\circ}\right.$ CNJ: 0494631-70.2014.8.21.7000). Relator: Des. Jayme Weingartner Neto, 11 de março de 2015. Disponível em: <http://www.tjrs.jus.br>. Acesso em 11 dez. 2017. 
Neste excerto, observamos que o desembargador apresenta no consequente do condicional ${ }^{28}$ a conjunção de, nos seus termos, três vetores para a aplicação da Lei Maria da Penha: relação íntima de afeto entre agressor e vítima, violência de gênero direcionada à prática delitiva contra mulher e situação de vulnerabilidade da vítima em relação ao agressor. Isso implica dizer que, conforme o relator, a Lei somente pode ser aplicada na presença cumulativa dos vetores. $\mathrm{O}$ caso não atende explicitamente ao segundo consequente do enunciado condicional, ou seja, trata-se de "vítima do sexo masculino". Resta evidente que, "em se tratando de lei que visa à proteção especial às mulheres", é "inviável acolher o presente pleito". ${ }^{29}$

$\mathrm{S}_{1}$ - O desembargador afirma que a fixação de competência para julgar casos de violência doméstica e familiar no âmbito dos Juizados de Violência Doméstica e Familiar, criados pela Lei 11.340/06 [Lei Maria da Penha], depende da análise de três vetores [relação íntima de afeto, violência de gênero contra mulher e vulnerabilidade] que [relação íntima de afeto, violência de gênero contra mulher e vulnerabilidade] indicam, quando [relação íntima de afeto, violência de gênero contra mulher e vulnerabilidade] estão presentes de forma cumulativa em casos de violência doméstica e familiar, a incidência da cognominada Lei Maria da Penha [Lei 11.340/06] (premissa implicada derivada da explicatura do primeiro enunciado do voto do desembargador). $\mathrm{S}_{2}-\mathrm{O}$ desembargador vota que é inviável reconhecer a incidência da Lei $\mathrm{n}^{0}$ 11.340/06 [Lei Maria da Penha] que [Lei Maria da Penha] visa coibir a violência de gênero no âmbito doméstico e familiar no caso dos autos de apelação interposto em face do indeferimento de medidas protetivas pleiteadas em favor de D.

\footnotetext{
${ }^{28}$ Dada uma formulação condicional padrão do tipo 'Se $P$, então $Q$ ' ou ' $P$ implica $Q$ ', definem-se por antecedentes do condicional os termos representados por $P$ que sucedem a conjunção 'se' e definem-se por consequentes do condicional os termos representados por $Q$ que sucedem a conjunção 'então'.

${ }^{29}$ Para reforçar o argumento, o desembargador acrescenta decisão precedente do STJ, segundo a qual o "sujeito passivo da violência doméstica, objeto da referida lei, é a mulher" e do TJ/RS, segundo a qual "a Lei no 11.340/2006 se aplica em proteção apenas às vítimas do sexo feminino, de modo que as medidas protetivas de urgência por ela reguladas não podem ser requeridas pelo homem em desfavor da mulher".
} 
S. G., uma vez D. S. G tratando-se de vítima do sexo masculino (conclusão implicada por modus ponens $S_{1} \rightarrow S_{2}$ ).

$\mathrm{S}_{3}-\mathrm{O}$ desembargador vota que é inviável acolher o pleito de recurso de apelação interposto em face do indeferimento de medidas protetivas pleiteadas em favor de D. S. G (conclusão implicada por modus ponens $\left.S_{2} \rightarrow S_{3}\right)^{30}$

O quinto caso refere-se a "conflito de competência suscitado pelo Juiz de Direito da $6^{\text {a }}$ Vara Criminal do Foro Central de Porto Alegre contra o Juiz de Direito do $1^{\circ}$ Juizado Especial Criminal do Foro Central de Porto Alegre", que também foi analisado pelo Des. Jayme Weingartner Neto. ${ }^{31}$ O Desembargador inicia seu voto colacionando parecer do Procurador de Justiça para, nos seus termos, "evitar tautologia". Seguem excertos do parecer.

Ocorre que, no caso, não se trata de delito previsto no âmbito da Lei 11.340/06. Não houve violência de homem contra mulher, houve, em tese, lesão corporal de natureza leve e ameaça praticadas por uma mulher contra um homem. A Lei Maria da Penha trata da violência contra a mulher no âmbito familiar, mais especificamente, da violência de homem contra mulher.

Logo, por não se tratar, no caso, de fato relacionado à violência do gênero, não está paliado por tal diploma legal. O sujeito passivo da violência doméstica, objeto da Lei 11.340/06, é a mulher, de modo que, em se tratando de vítima de gênero masculino, não se aplica tal diploma legal, o que retira a competência do juízo suscitante. [...]

Dessa forma, está-se a tratar, em tese, diante dos delitos previstos no art. 129, caput, e 147, ambos do Código Penal, a competência

${ }^{30}$ Em lógica proposicional, esse argumento poderia ser assim modelado: $P \rightarrow(Q \wedge R \wedge S)$ - Se a Lei Maria da Penha deve ser aplicada, então dever haver relação íntima de afeto, violência de gênero contra mulher e vulnerabilidade; $\neg \mathrm{R}$ - Não há violência de gênero contra mulher neste caso; $\neg \mathrm{P}-\mathrm{A}$ Lei Maria da Penha não deve ser aplicada neste caso; $\neg \mathrm{P} \rightarrow \mathrm{T}$ - Se a Lei Maria da Penha não deve ser aplicada neste caso, então é inviável acolher apelação; T - É inviável acolher apelação.

${ }^{31}$ RIO GRANDE DO SUL. Tribunal de Justiça. Conflito de jurisdição ${ }^{\circ} 70075577759$ ( $n^{\circ}$ CNJ: 0321890-19.2017.8.21.7000). Relator: Des. Jayme Weingartner Neto, 29 de novembro de 2017. Disponível em: <http://www.tjrs.jus.br>. Acesso em 11 dez. 2017. 
para julgar o fato é do Juizado Especial Criminal, ope legis. ${ }^{32}$ (grifos no original).

Nesse voto mais recente, Weingartner Neto produz um argumento condicional diferente daquele exarado em 2015. A aplicação da Lei Maria da Penha agora só é admitida quando houver "relações domésticas e familiares" e violência contra mulher. Nos seus termos, "ainda que se trata de delito envolvendo relações domésticas e familiares", o caso se refere a "vítima do sexo masculino", razão pela qual é "inviável a aplicação do rito da Lei Maria da Penha" e, por consequência, a competência do caso não deve ser do Juizado Especial Criminal. Em síntese, o sexo do sujeito passivo é, outra vez, suficiente para não aplicar a Lei.

O primeiro excerto pode ser assim modelado:

$\mathrm{S}_{1}$ - Houve, em tese, lesão corporal de natureza leve e ameaça praticadas por uma mulher contra um homem no caso de conflito de competência... (premissa implicada da explicatura dos enunciados do voto).

$\mathrm{S}_{2}$ - Não houve violência de homem contra mulher no caso de conflito de competência (premissa implicada da explicatura dos enunciados do voto).

$\mathrm{S}_{3}-\mathrm{O}$ caso de conflito de competência ... não constitui delito previsto no âmbito da Lei 11.340/06 [Lei Maria da Penha] (conclusão implicada por modus ponens conjuntivo: $\mathrm{S}_{1} \wedge \mathrm{S}_{2} \rightarrow \mathrm{S}_{3}$ ). $\mathrm{S}_{4}$ - A Lei Maria da Penha trata, mais especificamente, da violência de homem contra mulher no âmbito familiar (premissa implicada da explicatura dos enunciados do voto).

$\mathrm{S}_{5}$ - $\mathrm{O}$ caso de conflito de competência... não trata de fato relacionado à violência do gênero

$\mathrm{S}_{6}-\mathrm{O}$ caso de conflito de competência... não está paliado por tal diploma legal [Lei Maria da Penha] (conclusão implicada por modus ponens conjuntivo: $\left.\mathrm{S}_{4} \wedge \mathrm{S}_{5} \rightarrow \mathrm{S}_{6}\right)$.

$\mathrm{S}_{7}-\mathrm{O}$ sujeito passivo da violência doméstica e familiar objeto da Lei 11.340/06 [Lei Maria da Penha] é mulher.

$\mathrm{S}_{8}$ - A vítima [sujeito passivo da violência doméstica e familiar] é de gênero masculino [homem] no caso de conflito de competência... (premissa implicada da explicatura dos enunciados do voto).

${ }^{32}$ Expressão latina que significa "por força da lei". 
$\mathrm{S}_{9}$ - Não se aplica tal diploma legal [A Lei Maria da Penha] ao caso de conflito de competência... (conclusão implicada por modus ponens conjuntivo: $\mathrm{S}_{7} \wedge \mathrm{S}_{8} \rightarrow \mathrm{S}_{9}$ ).

$\mathrm{S}_{10}-\mathrm{O}$ fato de a Lei Maria da Penha não se aplicar ao caso de conflito de competência... retira a competência do juízo suscitante

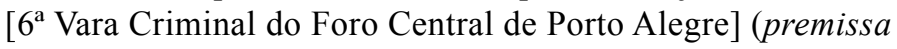
implicada da explicatura dos enunciados do voto).

$\mathrm{S}_{11}$ - $\mathrm{O}$ caso de conflito de competência... trata de delitos previstos no art. 129, caput, e 147, ambos do Código Penal (premissa implicada da explicatura dos enunciados do voto).

$\mathrm{S}_{12}$ - A competência para julgar o fato é do Juizado Especial Criminal Criminal do Foro Central de Porto Alegre, ope legis (conclusão implicada por modus ponens conjuntivo: $\left.\mathrm{S}_{10} \wedge \mathrm{S}_{11} \rightarrow \mathrm{S}_{12}\right) .{ }^{33}$

\section{Weingartner Neto complementa:}

Em suma, é da essência do conceito legal de violência doméstica e familiar, para efeitos de aplicação da legislação especial protetiva (e, vale lembra, mais gravosa para o sujeito ativo do delito, o que implica cuidado com o princípio constitucional da reserva legal), ação ou omissão, contra mulher, baseada no gênero, independente de orientação sexual - mas não do sexo (artigo 5", "caput" e parágrafo único da Lei 11.340/2006).

Tratando-se, portanto, de vítima do sexo masculino, inviável a aplicação do rito da Lei Maria da Penha, ainda que se trata de delito envolvendo relações domésticas e familiares. (grifos nossos).

\section{Considerações finais}

Considerados os avanços da Lei Maria da Penha (2006) para a proteção de vítimas femininas de violência doméstica e familiar em geral, persistem em aberto aspectos teóricos sobre sua aplicação, entre os quais

${ }^{33}$ Em lógica proposicional, esse argumento poderia ser assim modelado: $\mathrm{P} \rightarrow(\mathrm{Q} \wedge \mathrm{R})$ - Se a Lei Maria da Penha deve ser aplicada, então dever haver relações domésticas e familiares e a vítima deve ser mulher; $\neg \mathrm{R}-\mathrm{Não}$ há vítima mulher neste caso; $\neg \mathrm{P}-\mathrm{A}$ Lei Maria da Penha não deve ser aplicada neste caso; $\neg \mathrm{P} \rightarrow \mathrm{Q}-$ Se a Lei Maria da Penha não deve ser aplicada ao caso, então o conflito de competência deve ser acolhido; $\neg \mathrm{P}$ - A Lei Maria da Penha não deve ser aplicada ao caso; Q - O conflito de competência deve ser acolhido. 
a questão de escopo. Se, de um lado, tem-se admitido na jurisprudência uma interpretação mais alargada que acolhe transexuais femininas, travestis, drag queens e transformistas e faz prevalecer uma interpretação do item lexical 'mulher' como gênero, aspecto mais controverso é sua aplicação por analogia a vítimas heteroafetivas masculinas. Posto isso, analisamos jurisprudências sobre a extensão do escopo da Lei Maria da Penha a homens heteroafetivos vítimas de violência doméstica e familiar com base no aparato descritivo e explanatório da teoria de conciliação de metas de Rauen $(2013,2014)$ e teoria da relevância de Sperber e Wilson (1995 [1986]), investigando se os tribunais acolhem esta hipótese de extensão e observando a respectiva argumentação.

Tendo sido selecionados cinco casos, os resultados sugerem haver uma interpretação categórica sobre o tema nos tribunais da região sul do Brasil, segundo a qual a Lei Maria da Penha deve ser aplicada somente em casos onde o sujeito passivo de violência doméstica e familiar é mulher. Em comum, as decisões referem-se a conflitos de competência entre varas especiais que tratam de violência doméstica e familiar e varas que abrangem demais situações do Direito Penal. Para dirimir esses conflitos (meta $Q$ ), todos os relatores utilizaram-se de argumentos em dois estágios, de tal modo a se posicionam em favor da inaplicabilidade da Lei (submeta $P$ ), destacando que o sujeito passivo nesses casos é masculino (ação $O$ ).

Em essência, há um recuo a uma interpretação default ou mais "literal" do item lexical 'mulher' no texto do art. $5^{\circ}$ da Lei, enquanto SER HUMANO DO SEXO FEMININO. Uma vez que a vítima de agressão não é mulher, resta concluir por negação do consequente que a Lei é inaplicável às lides; e uma vez que a Lei Maria não deve ser aplicada a vítimas masculinas, resta concluir por afirmação do antecedente que procede o conflito de competência.

\section{Agradecimentos}

Os autores agradecem as contribuições pertinentes dos consultores da Revista de Estudos da Linguagem para o aperfeiçoamento do presente texto e assumem integral responsabilidade pelos equívocos remanescentes. Ademais, agradecem o Programa Unisul de Iniciação Científica (PUIC) pela viabilização do estudo.

\section{Declaração de autoria}


Declaramos que o texto foi redigido integralmente pelos dois autores. $\mathrm{O}$ primeiro autor é mais diretamente responsável pelo aporte teórico e pela metodologia descritivo-explanatória. O segundo autor é mais diretamente responsável pelo aporte das informações do campo do direito e pela prospecção e seleção do corpus.

\section{Referências}

ARAUJO, L. A. D.; NUNES JÚNIOR, V. S. Curso de direito constitucional. 7. ed. São Paulo: Saraiva, 2003.

BIANCHINI, A. Lei Maria da Penha: Lei N. 11.340/206: aspectos assistenciais, protetivos e criminais da violência de gênero. 2. ed. São Paulo: Saraiva, 2014

BRASIL. Presidência da República. Casa Civil. Subchefia para Assuntos Jurídicos. Lei n ${ }^{\circ}$ 11.340, de 7 de agosto de 2006. Diário Oficial da União, Brasília, DF, 7 ago. 2006. Disponível em: <http://www.planalto.gov.br/ ccivil 03/ ato2004-2006/2006/lei/111340.htm>. Acesso em: 23 maio 2014.

BRASIL. Constituição da República Federativa do Brasil, 1988. Brasília: Senado Federal, Centro Gráfico, 1988. Disponível em: $<$ http://www.planalto. gov.br/ccivil_03/constituicao/constituicao.htm>. Acesso em: 23 maio 2014.

CAIXETA, M. M. Violência doméstica contra o gênero masculino. 2011. 81 f. Monografia (Bacharelado em Direito) - Faculdade de Direito, Centro Universitário de Brasília, Brasília, 2011.

DIAS, M. B.; REINHEIMER, T. L. Da violência contra a mulher como uma violação de direitos humanos - artigo $6^{\circ}$. In: CAMPOS, C. H. de (Org.). Lei Maria da Penha comentada em uma perspectiva jurídicofeminista. São Paulo: Lumen Juris, 2011. p. 195-200.

HARMAN, G. The inference to the best explanation. Philosophical Review, Durham, v. 74, p. 88-95, 1965. Doi: https://doi.org/10.2307/2183532

LARRAURI, E. Mujeres, derecho penal y criminología. Madrid: Siglo Veinteuno, 1994.

MAIA, A. P.; BEZERRA, L. P. Transexuais e o direito à identidade de gênero: a interlocução entre os princípios da dignidade da pessoa humana, da igualdade e da liberdade. Quaestio Iuris, Rio de Janeiro, v. 10, n. 3, p. 1688-1717, 2017. 
NUCCI, G. de S. Manual de direito penal. 9. ed. São Paulo: Revista dos Tribunais, 2013.

OEA. Comissão Interamericana de Direitos Humanos, Caso 12.051, Relatório 54/01, Maria da Penha Maia Fernandes. Brasil, 2001. Disponível em: <http://www.sbdp.org.br/arquivos/material/299 Relat\%20n.pdf>. Acesso em: 22 out. 2017.

PARANÁ. Tribunal de Justiça. Conflito de competência crime n ${ }^{\circ} 647.834$ 8. Relator: Des. Luiz Osório Moraes Panza, 25 de fevereiro de 2010. Disponível em: <http://www.tjpr.jus.br>. Acesso em 11 dez. 2017.

PELICANI, R. B. A Lei Maria da Penha e o princípio da igualdade: interpretação conforme a Constituição. Revista do Curso de Direito, São Paulo, v. 4, n. 4, p. 237-262, 2007.

PIMENTEL, S. Convenção sobre a eliminação de todas as formas de discriminação contra a mulher. 1979. Disponível em: <http://www. onumulheres.org.br/wp-content/uploads/2013/03/convencao_cedaw. pdf $>$. Acesso em: 22 out. 2017.

PSILLOS, S. Simple the best: A Case for Abduction. In: KAKAS, A. C.; SADRI, F. (eds.). Computational Logic: Logic Programming and Beyond. Berlin: Springer-Verlag, 2002. p. 605-626. Disponível em: $<$ http://www. phs.uoa.gr/ psillos/>. Acesso em: 2 set. 2013.

RAUEN, B. M. Aplicação da Lei Maria da Penha em casos envolvendo vítimas transexuais femininas: análise fundamentada no conceito de violência de gênero em jurisprudências selecionadas de tribunais de justiça. 2017. 82 f. Monografia (Bacharelado em Direito) - Faculdade de Direito, Universidade do Sul de Santa Catarina, Tubarão, 2017.

RAUEN, B. M. Extensão do escopo da Lei Maria da Penha a homens vítimas de violência doméstica e familiar em Pelicani (2007): análise de viés pragmático cognitivo, 2015. 5 f. Projeto (Iniciação Científica) - Faculdade de Direito, Universidade do Sul de Santa Catarina, Tubarão, 2015.

RAUEN, F. J. Por uma modelação abdutivo-dedutiva de interações comunicativas. In: TENUTA, A. M.; COELHO, S. M. (Org.). Uma abordagem cognitiva da linguagem [livro eletrônico]: perspectivas teóricas e descritivas. Belo Horizonte: FALE/UFMG, 2018. p. 13-29.

RAUEN, F. J. Hipóteses abdutivas antefactuais e modelação proativa de metas. Signo, Santa Cruz do Sul, v. 38, n. 65, p. 188-204, 2013. 
RAUEN, F. J. For a goal conciliation theory: ante-factual abductive hypotheses and proactive modelling. Linguagem em (Dis)curso, Tubarão, v. 14, n. 3, p. 595-625, 2014.

RAUEN, F. J. Roteiros de iniciação científica: os primeiros passos da pesquisa científica desde a concepção até a produção e a apresentação. Palhoça: Ed. da Unisul, 2015.

RAUEN, F. J.; RAUEN, B. M. Extensão do escopo da Lei Maria da Penha a homens vítimas de violência doméstica e familiar em Pelicani (2007): uma análise pragmático-cognitiva. 2018. Inédito.

RIO GRANDE DO SUL. Tribunal de Justiça. Conflito de jurisdição $n^{o} 70075577759$ ( $n^{\circ}$ CNJ: 0321890-19.2017.8.21.7000). Relator: Des. Jayme Weingartner Neto, 29 de novembro de 2017. Disponível em: $<$ http://www.tjrs.jus.br>. Acesso em 11 dez. 2017.

RIO GRANDE DO SUL. Tribunal de Justiça. Conflito de jurisdição $n^{o}$ 70062842471 ( $n^{\circ}$ CNJ: 0476810-53.2014.8.21.7000). Relator: Des. Luiz Mello Guimarães, 12 de fevereiro de 2015. Disponível em: $<$ http://www. tjrs.jus.br>. Acesso em 11 dez. 2017.

RIO GRANDE DO SUL. Tribunal de Justiça. Apelação crime $n^{o}$ 70063020689 ( $n^{\circ}$ CNJ: 0494631-70.2014.8.21.7000). Relator: Des. Jayme Weingartner Neto, 11 de março de 2015. Disponível em: $<$ http:// www.tjrs.jus.br>. Acesso em 11 dez. 2017.

RIO GRANDE DO SUL. Tribunal de Justiça. Conflito de Jurisdição $n^{o}$ 70044908549. Relator: Des. Marco Aurélio de Oliveira Canosa, 10 de maio de 2012. Disponível em: <http://www.tjrs.jus.br>. Acesso em 11 dez. 2017.

SILVEIRA, J. R. C. da; FELTES, H. P. de M. Pragmática e cognição: a textualidade pela relevância. 3. ed. Porto Alegre: Edipucrs, 2002.

SOUZA, S. R. de. Comentários à lei de combate à violência contra a mulher. 3. ed. Curitiba: Juruá, 2009.

SPERBER, D.; CLÉMENT, F.; HEINTZ, C.; MASCARO, O.; MERCIER, H.; ORIGGI, G.; WILSON, D. Epistemic vigilance. Mind \& Language, Wiley Blackwel, v. 25, n. 4, p. 359-393, 2010.

SPERBER, D.; WILSON, D. Relevance: communication and cognition. 2nd. ed. Oxford: Blackwell, 1995. [1st ed. 1986]. 